\title{
Scaffolding a Presentation: Comments from Spanish and German
}

\author{
Paul Nissler \\ Stanford University, Stanford, California, USA
}

\begin{abstract}
This paper considers implementation of a 'scaffolding' method as a means towards successful 'presentations' and acquisition of presentational language in the classroom and beyond. Setting-up a concrete, well articulated and culturally nuanced yet personalized scaffolding for acquiring upper-level language in working towards and performing presentations will be explored. Specific experiences from Second-Year language classes in both Spanish and then German are considered. Setting clear objectives in a personalized atmosphere and issues of development of transferable professional skills will be further contemplated.
\end{abstract}

Index Terms—-presentations, presentational language, transferable skills, scaffolding, German, Spanish

\section{INTRODUCTION}

Giving a good presentation, whether in a foreign or one's native language, involves preparation and practice. Presentations, in the dominant PowerPoint (or prezi) format, tend to be performed within traditional academic, politicaldiplomatic and broad professional, especially marketing events/forums. This continues to evolve and change since the advent of the internet and hybrid-spaces and institutional and social evolutions. With this background, I would like to engage with the already established discussion of the 'presentation' and its role in language learning. Precisely, I consider the presentation (and the broader "presentational language" as defined by ACTFL) incrementally more important as language learners aspire to progress to ever higher levels of second-language proficiency. This 'higher registry' of language often required in giving an 'academic' or 'business' presentation can be acquired in foreign language classes, within an integrated implementation. Here I have found scaffolding a particularly useful strategy.

What does 'scaffolding' mean within the framework of developing 'presentational' language and preparing for a presentation? Scaffolding, in it's most common understanding is that of constructing, often makeshift structure around the development of a foundation and the permanent structure built upon this; as in construction and constructing a new or sanitizing or repairing/renovating an existing building. Relating scaffolding in traditional construction to scaffolding of a presentation offers an interesting and arguably very useful metaphor and reference for foreign language teachers and learners. One obviously needs blueprints and a plan in construction, as in developing a successful presentation. In 'setting' up the 'scaffolding', one is enabled to build. Within the scaffolding, above ground-level, perhaps even high above the ground, one is or develops a certain confidence in their task/activity. Once the activity/task is done, the scaffolding can come down, and the renovated or new building, structure, or in 'presentation', a finished product, stands alone, independently. 'Scaffolding' helped in this particular case, but becomes a 'strategy' then in future 'production'. It is a means of enabling. Here this can be concretely used in language learning classes, as well as then acquired by students to apply to situations outside of their language classrooms, both pertaining to language as well as beyond. This then contributes to the broader development of the much talked about 'transferable' skills (Berman).

\section{Methodology}

At this point I would like to concretize the idea of scaffolding and presentational language with some examples from beginning second-year German and Spanish language classroom experiences at the university. In the following paper my particular focus will be to look, first individually and then comparatively, at multiple week preparations for presentations in these classes. Here using "presentational language" in trying to get the students actively using language typical of presentations, as well as invoking structure and confidence typical of presentations structured/outlined in a sort of "scaffolding", in first-quarter second-year classes. Before proceeding, the entering proficiency of the students would be useful to orientate ourselves here: according to our institution's proficiency goals, these students should be solid IM speakers (according to ACTFL standards), IH writers, orally pushing into an IM+ level, some even IH-, and writing at a baseline AL by the end of the quarter. Actual results though vary from quarter to quarter, and year to year of course. And although I will be focusing on beginning second-year courses, 'presentations' and 'presentational language' play an incrementally important role from first-year through advanced language courses (evidenced in fruitful discussion with and work by Ali Miano in Spanish, Ana Cellinese in Italian and Heather Howard in French).

Here I would like considering how scaffolding is integrated and realized by first looking concretely at Spanish, and then the German class. As in all of the language courses at our institution, we work within a broader framework the whole 10-week quarter on developing proficiency and working towards particular curricular objectives. This is multi- 
faceted and all the classical competencies (i.e. reading, writing, listening and speaking) are intermixed and overlap, accordingly, towards these goals. Within this dynamic, the presentation and "presentational language" plays an increasingly important role, not isolated, but integrated, in the second-year and beyond. This means integrating amidst the dynamic of working through parts of a textbook with readings, videos clips, and new thematic vocabularies along with customized authentic video and reading links within the in-class in-person and out-of-class online communication/exchanges, interactions and activities. Scaffolding a presentation involves preparation. "Fang nie mit dem Anfang an, sondern immer drei Meilen vor dem Anfang!" [Never start at the beginning, but rather three miles before that] writes the German author, satirist, journalist Kurt Tucholsky (1930) in his short essay ,"Ratschläge für einen schlechten Redner" [Advise for a bad speaker]. Scaffolding starts well before - I am not sure what it would be in miles - a presentation; I think Tucholsky would agree.

\section{RESUltS AND ANALYSIS IN SPANISH}

Turning our attention to the beginning of the class; one of the first steps in preparing in the Spanish course was already in the first week to explain to students the guidelines of the presentation (e.g. length, format - with beginning, connected main parts and conclusion with follow-up discussion, dates, aspects of audience interaction, required handout). They were also given a quite extended vocabulary list - with examples of how to introduce, connect, conclude a topic as well as how to acknowledge someone else's opinion, state your own, compare and contrast, amongst many further tasks. ${ }^{1}$ The presentations were to be well-outlined ahead of time, with mini-practice sessions well before the actual presentations. Here, the 'form' and even 'space' of a traditional presentation was/is continually questioned, challenged, reflected upon and even re-defined. The presentations were to be given in a panel-type structure, with 3-4 presenters presenting for an allotted time (10+ minutes for the first, then $15+$ minutes for the final presentation), then the whole panel was to field questions from their audience. Each audience member would be given a handout with pertinent information, in outline form, to the presentation and then was also required to ask questions. We also/or particularly (considering the level of the students speech and the upper-level of the presentation topics) worked on how to ask a question at the advanced/superior level - i.e. here situating the question contextually, making reference to something said in the presentation, then including perhaps a personal, i.e. student's take on the topic and then leaving it in the presenter's arena. From the moment of the list's introduction into class, the students were to pick out at least 3 sayings (sentences starters, connectors, etc...) to use in each class (or part thereof) during class-time partner/group/plenum discussions and activities. We continued with this into the second week (and thereafter).

Although scaffolding in general may seem standardized and even quite technical (although it can be adjusted and manipulated to conform to any structure, perhaps better the process of setting it up is more standardized than the scaffolding's structural aspect), thinking and the art of expressing this is less so; it is very personal, subjective and even artistic. Here recognizing each individual's, each student's (hence also each class as a unique body of unique individuals) way of thinking and expression of this, within the larger structure of a class with proficiency goals and curricular objectives, I asked students to reflect on how they think and how they speak. However first, I modeled this for them - I shared with them how I think I think and how I think I express myself in my native language about this, translating this accordingly into the target language Spanish, in a sort of handwritten flow chart, or as I termed it in Spanish, organigrama. I felt that superimposing a way of thinking and a way of expressing this onto them (i.e. showing them exactly what to say and how to order this) would only further alienate them from owning their second language production. Understanding that producing this upper-registry language (working towards the more formal setting/structure of an academic presentation) if disconnected from themselves in their understanding of their own language production, would become even further alien and artificial, superficial, if not understood of an interlinked, overlapping self in time and space.

\footnotetext{
${ }^{1}$ This list has been used and is continually edited and added to by numerous Spanish lecturers at Stanford, initiated by my colleagues Citlalli del Carpio and Spanish Language Coordinator Ali Miano, and partially based off of work by Professor Guadalupe Valdes.
} 


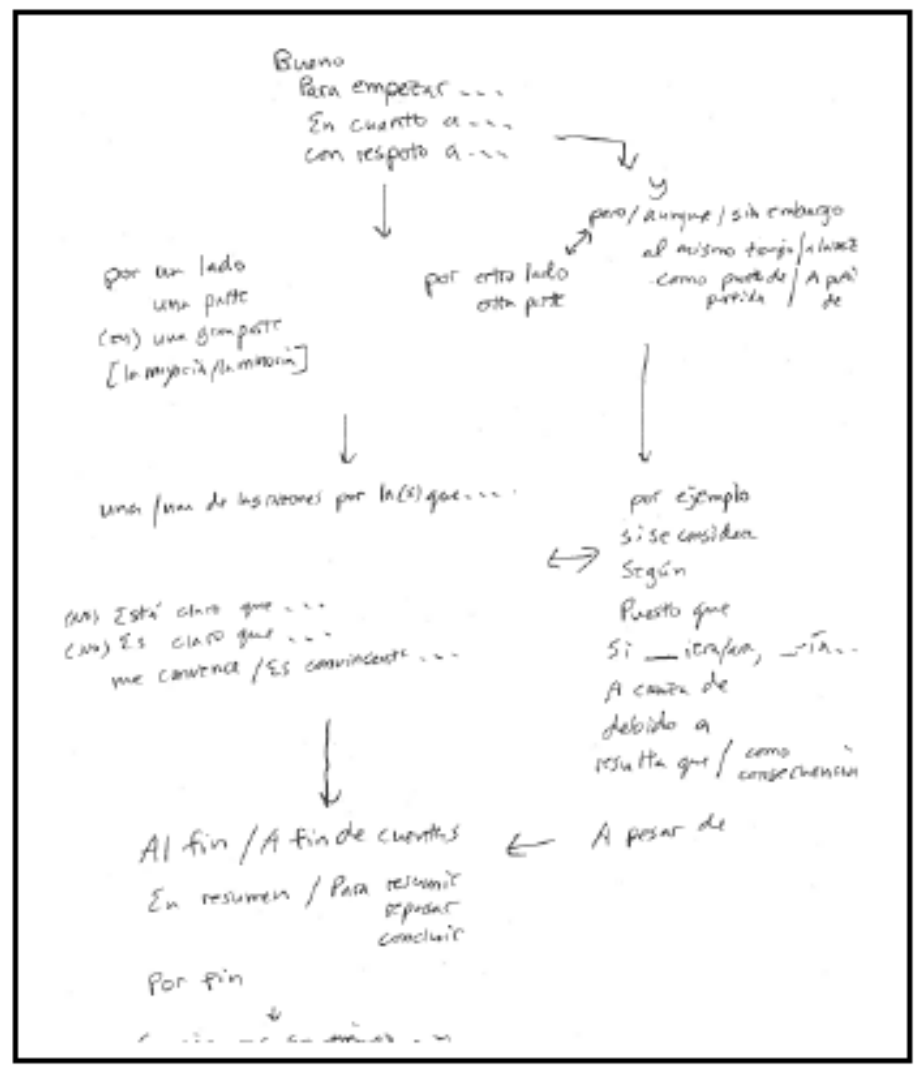

Figure 1. Organigrama

So, on the first day of week three I presented them with a visual result of my reflections of my thinking, my expression of this as a flow chart, or 'organigrama' (Figure 1) to model a personalized scaffolding of language and structure. Then, they were to present their own on the second day (encouraged to draw and write this out by hand) and test it out as well as add to it in the proceeding classes as well as for the rest of the quarter. The activities/tasks outlined thus far speak to scaffolding for the students' first, then second presentations in the class (week 5, then week 10). However, the skills developed in these activities were practiced in a variety of contexts and a variety of further classroom activities/task, were not expressedly focused on 'presentations', they overlap with aspects of the presentations, and together work towards overall proficiency. During this all, to note here: explanations were short/curt, to the point and interactive. Here they practiced in short mini-doses starting, connecting, and concluding ideas as well as narrating and describing (all important in the Advanced-level) - interweaving book, potential presentation and personal themes and always also keeping in mind our program objectives/class goals and levels (i.e. working into IM+). Here, for example, moments with narration, description and their linguistic introductions, connectors and conclusions in online interviews (J. Sabina and J. Serat) and documentaries (i.e. 1970s/80s critical theater group) were isolated and used in modeling activities. Examples were from Spain, overlapping with the geographical and cultural focus in the textbook in the first part of the quarter.

During the first round of presentations in the fourth and fifth weeks students gave their presentation and when not presenting, actively took part in the audience (i.e. listening, asking questions, and discussing afterwards). Here we had also explicitly worked on and practiced how to refer to a topic or part of presentation (e.g. en cuanto a../con respeto a... - which if unknown, can really damper a student's initiative). Presentations averaged 8-12 minutes, a discussion thereafter brought the overall total to 15 minutes. Out of a class of around 15 students, each student was required to ask at least one question per panel (hence 4-5 questions per panelist). Presenters fielded audience member's questions spontaneously. All students performed, linguistically and within broader proficiency, within (even excelling) the range of hoped target levels and performance.

In considering evaluating and improving; their presentations were filmed and then uploaded to a personal dropbox online - here they were to self-evaluate their presentations and hand in to me/instructor a self-critique - I then gave them feedback once having received their self-evaluation (based off of our curricular objectives and proficiency guidelines). In my comments to them individually, I especially focused on their openings (al principio/para empezar...) and closings, securing up basic vocabulary (for some) - such as gustar/haber/ser - and encouraging using variance/nuances here (instead of just repeating the same verb/adjective) and simple structures. Remembering Tucholsky, and the unfortunate many boring presentations I (we all) have listened to/experienced, and occasionally given, I wanted to raise the presenters' consciousness of their audience when talking (i.e. not just read a paper before their audience) - here opening, connecting and closing with eye-contact and consideration of their audience. 
Reflecting on overall transferable skills, especially here concerning communication, even the presentation - as artistically expressed by the likes of German theoreticians/thinkers Walter Benjamin, B. Brecht or later Hans Maganus Enzensberger (in writings on communication in literature, theater, radio and broader media), is not an Einbahnstrasse (one-way street). Within ACTFL's definition, this should be understood in the "real world of language" to take many forms, for example, a hybrid interpersonal-presentational or simply the interaction between the presentationalinterpersonal-interpretive if whole of presentation-discussion is considered. In the complexities of 'real-world' language production and communication - with computers, tablets, cell phones, paper, and 'in-person' live that is projected, seen and heard, seen and read, heard but not seen, seen and heard delayed, seen and heard live, etc..., involves an engagement in understanding and appropriate/corresponding practicing. Hence, the scaffolding is directly constructed for the immediate task of the presentation in class, however the skills acquired during this process and the overlapping tasks during this time, benefit the student beyond the designed classroom space and time (i.e. for future academic and professional presentations, future inactions and production in second-language as well as broader firstlanguage nuance within upper-level or more formal and/or professional correspondence).

After each 'panel' of presentations and their respective discussions, I would make some overall general comments to the patterns of errors - which were noted by the upcoming presenters and improved upon (i.e. digested). In weeks six, seven and eight, amidst the numerous activities in and outside of class, students worked on papers. They also worked on their second and final presentation which would be an extension of one of their papers from the quarter. They continued to actively incorporate new connectors/sentence starters into their speech in class as well as develop (i.e. add to) their flow charts (i.e. organigramas).

In thinking of modeling and extending the spatial and temporal concept of presentation beyond traditional academic, a few experiences were induced to these means. Beforehand, in week 5 and 6 I invited a visiting scholar - currently professor on the East coast (Queens College) and accomplished presenter, to give a short academic presentation on his area of expertise which is issues surrounding language, identity and power with a focus in the Dominican Republic/and broader Caribbean. The students were given a handout pertaining to the presentation as well as asked to prepare questions for the speaker beforehand - and during the presentation/i.e. for discussion immediately after the presentation. During the presentation (which was also filmed) the students were asked to not only concentrate on the content, but also the overall style and structure of the presentation and the language used. We had an extremely successful, fruitful discussion after the presentation (e.g. some students wrote it was the highlight of the class and wished for more in their course evaluations). Another modeling activity was a guest lecture event with a short theater performance, documentary film, and lecture from a local non-profit group concerned with the disappearance of many women (femicidio), and journalists, in Juarez Mexico. Students in all three Spanish Language classes in the second year were invited to take part. Students in my beginning second-year class were intellectually and critically comparable, if not even surpassing, the involvement in the event of those in more advanced classes. Impressively, more than half of my class was able to engage with the visitors, asking quite critical questions, and here being able to contextualize it as well. A final modeling activity was the showing of a presentation, exemplified in a film of historical and cultural resonance. The final speech of the Mexican actor Cantiflas in his film Su Excelencia (1967), exhibits satire and comedy, but also a critical political view of the 'non-aligned' and context for the students to pick up on. Students were prepared with some background information to Mexican film, Cantiflas as well as Mexico, Latin America and the Cold War. The examples from the Caribbean and Mexico overlapped with the geographical focus in the students' text book at this moment in the class. Students had access to the film in our media library and were to watch this final speech and react to it, both its content, as well as the structure and the language in the speech. Both for students' presentations as well as the guest presentation, event and film speech, I organized forums on our course's website space for students to post audio posts (we also did written posts) - with varying tasks. Usually, it would be to react to one of the presentations - then make sure to listen to a previous post and include a comment to another student's post within their post (i.e. reference another student's post) so that there would be some sort of ongoing string of communication. Through the linking in-class spoken, online written and spoken uploads, there developed a sort of hybrid written-spoken space using 'presentational' language working towards their final presentations, within the broader structure/format of the overall class, proficiency goals, curricular objectives and transferable skills.

In week eight students were to give mini-synopsis of their presentations to partners in class - first 3 minutes, then with a second partner for 1 minute. They were to introduce their topic, give a very abbreviated structure outline and then conclude. Then, they did this again, practicing their ability to re-cast, re-formulate and be more efficient. They were to give each other feedback as well. Here in their feedback, they were to express overall potential interest of their audience and voice any suggestions to make it more interesting, i.e. to increase the potential for their audience to connect to the topic and presentation. Furthermore, they commented on the language and any outstanding holes or gaps pertaining to content. In weeks nine and ten, the students presented their second and final presentations - which were filmed, discussed in a panel setting and then were self-evaluated (with additional reflection and comparison of their language from first to second presentation). These final presentations were longer, more polished linguistically and structurally and were given with overall greater confidence.

After the quarter, I feel that a lot of higher-level language was learned and used by the students. I think that they also raised their consciousness as to prepping and giving an academic presentation in Spanish, as well as overall (to further 
note here is the fact that there were many first-year/freshman students who were still learning academic procedures/forms, although some upper class ones as well) and their language production and structuring of such overall. However, I also feel that a bit too much emphasis was given to presentational language whereas the students may had been able to make greater strides by not being as forced to work with this language and solidify what they had. One also has to ask the usefulness of this; ie. what are the goals and aspirations of the students: most want to use the language to studying-abroad, to use language more conversationally and only a small fraction aspired to use it professionally in an academic or other professional setting. Here, consistent surveys and questionnaires could be given and used to continually make adjustments to programs/classes and their corresponding objectives and goals.

\section{RESUlts AND ANALYSIS IN GERMAN}

Scaffolding for a presentation was, as in Spanish, also worked on in a beginning second-year German class. Here, students were to actively prep for a first and then a second presentation amidst working through themes pertaining to chapters in the textbook (listening, readings) and engaging in further in-class (authentic video and reading materials serving as cultural nuance and points of departure to discussion/activities) and online activities (such as Google Webdoc journals, online forums discussions, out-of-class cultural excursions, a.o.). At the beginning of the quarter, students were explained the German presentation's guidelines (i.e. time length, choosing theme, organizing structure/language and preparing). Here they were given lists of useful expressions in introducing, connecting, concluding, agreeing, disagreeing, comparing, etc.. These were printed out for the students on colored paper, i.e. not white, so that amongst their papers and notes, it would stick out and students would know to take it and have it beside them to reference every day in class. Many textbooks have lists of such expressions. There is also a plethora of such lists online in German, more so than in Spanish. There are even elaborate PowerPoints on professional presentations, including overall advise, format, techniques and language, easily found online, this was linked to our courses website for the students. In the weeks leading up to the presentations, students were to select examples and actively use new expressions and vocabulary in each class. I showed them here a flow chart of how one could open a topic (Was...angeht,im Bezug auf...., Wenn an....denkt, ), develop it (darüber hinaus/zum Beispiel/genauer gesagt...), compare (im Vergleich $\mathrm{zu} / \mathrm{verglichen} \mathrm{mit...)} \mathrm{and} \mathrm{contrast} \mathrm{(einerseits/auf} \mathrm{einer} \mathrm{Seite..-} \mathrm{andererseits/auf} \mathrm{der} \mathrm{anderen} \mathrm{Seite)} \mathrm{in} \mathrm{a} \mathrm{sort} \mathrm{of} \mathrm{flow} \mathrm{chart}$ of ideas. As in the Spanish organigrama, I modeled how I personally may think and express this, then encouraged them to think about how they think and would express this themselves and here develop their own flow chart, or Denk- and Argumentsablauf (Figure 2). The actively incorporated aspects of their flow chart within classroom activities in the first few weeks, discussing a reading, reacting to a video clip, developing a conversation within further class topics, students especially worked on introducing, connecting and closing language (as well as, later, recognizing statements of other person as they add/give their opinion). Thus, they developed a sense of the structure of an academic presentation, aspects which were consciously build into activities. In week 3 and 4, they watched and engaged with 2-3 short clips or parts of professional and academic presentations as models.

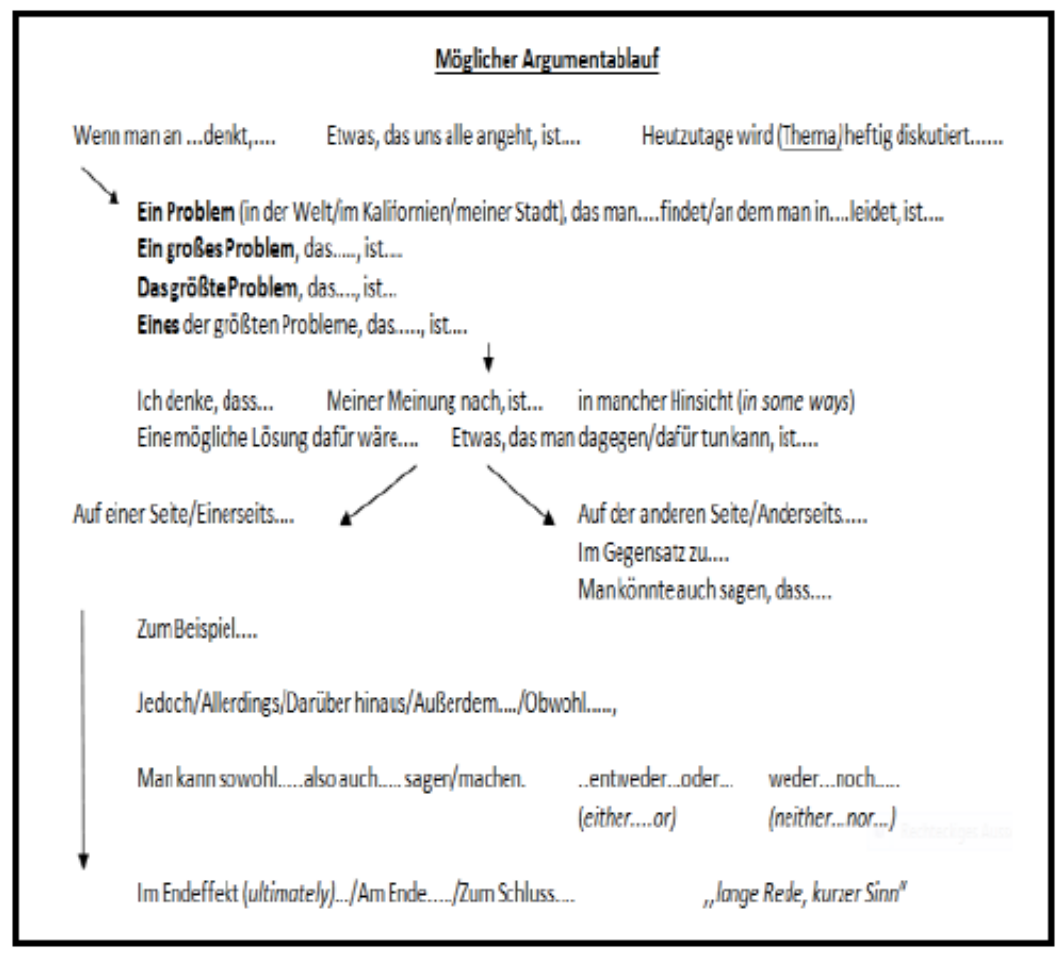

Figure 2. Argumentsablauf 
Here to, again, understand the content, but even also key into the structure and language used. In comparison to searching for Spanish examples, there were many more and easier to find German presentational examples online. I primarily found a plethora of useful models via youtube, entering in either the term Referat (more within the school or sometimes university setting), Vortrag (often times at professional or academic conferences) or Präsentation (taken from English, a bit broader in the spectrum) followed by the theme of such a presentation I was hoping to find. If found online, they are then easily utilized in class and also accessible for students further viewing outside of class (as a link in our class' website). Before giving their first presentation, they also were to give a short synopsis to a fellow student, including: intro, why they chose their topic and why/how it could be interesting for their peers, rough structure, and conclusion. The student listening should take notes and give their partner feedback, such as suggestions for improvement and things to include. A further possibility here is to alternatively and/or additionally give a short synopsis to their instructor outside of class. An additional further activities before giving their presentation, they could give brief summaries of their presentation to a partner, then rehash to others what their partner's or partners' presentation(s) was (were) about (sort of warming up the theme - and the presenter, and getting everyone familiar with basic vocabulary potentially issues relating to the presentation). The presentations were filmed and uploaded to dropbox - and each student was to self-evaluate their own presentation based on a double-sided handout (based off of our Gerlang curricular documents and further German-language presentational resources). All students were required to take notes to each presentation and then respond, comment and ask questions to individual presenters (this could alternatively also be done shortly before their second presentation (i.e. creating some distance). Students received feedback from their first presentation upon turning in self-criticism based upon having seen their uploaded presentation. Personalized areas for improvement were focused on by each individual student (follow up by instructor) in moving towards the final presentation (weeks 6-9). Here writing activities (Webdocs, Forums) encouraged practicing of different functions of presentations and required use of specific language as well (i.e. use of Redemittel for comparison, giving opinion, etc..). A further inclusion of ODAs (oral diagnostic assessments) and WDAs (written diagnostic assessment), which are used across language curriculum at our institution, offered an online space for students to further practice description, narration, comparison and even light speculation and hypothesis (the latter more so in second- and third class sequence of second-year). Spontaneous as well as prepared activities played a role in working towards final presentations. Model presentations in German were further posted online for students to analyze. Students also had opportunities to visit campus talks and were to note structure and language of presentations in English but relating to German world (e.g. Rösler (politician), Joffe (newspaper editor)). Not only high frequent structures (as in PowerPoint) were to be memorized (within personality) and actively incorporated, but also useful grammatical structures refined (subjunctive wenn..../als ob...., passive with modal verbs as well as heightened ability to re-phrase/re-cast in nuancing vocabulary (sehr/viel/überhaupt/nähmlich/überwiegend/wesentlich)). Final presentations were filmed and students submitted a selfreflection based on this final presentation and in comparison to the first (i.e. with improvement as well as continued areas (or new) of difficulty and ideas for ways they can improve). Students were required to ask questions of each presenter. If time is constrained, discussion could take place online. In conclusion here, students showed a great refinement of overall language (conjugating with modal verbs, verb/word placement, adjective endings, precision, ease in responses) and were enthused to watch and see selves for both presentations (i.e. and associate themselves and speaking the target foreign language).

As students enter into the second and then final class of the second-year German, they continue to work on presentations and presentational language. Depending on the quarter/semester, students are (as stated above) encouraged to visit campus or area talks (for example at the Goethe Institute or other universities or professional forums). One quarter, a graduate student in German with experience in the Olympics came to give a critical and culturally nuanced presentation on sports in Germany. Students were notified beforehand. The presentation was filmed and students took notes on the content, structure and language used. The presentation itself was very interactive and the proceeding discussion was lively and long. Another example, being in the Bay Area and start-up mecca, through personal acquaintances, two Austrian venture capitalists were invited to give a short talk. German classes from the end of $1^{\text {st }}$ year through the whole of the second year were invited (some required) to come. They gave a presentation and then lead a discussion on being a start-up and start-up culture in Austria and the US.

Honing in on one particular class' first presentations (and first implementation of a loose scaffolding for presentational language), students were able to connect temporally using “zuerst, dann...zum Schluss....jetzt muss ich den zweiten Punkt erklaeren...es geht um...., Es gibt Ursache - and employ appropriate-level vocabulary and even some more complicated structures "weil/obwohl..." "- with some self-corrections. Sometimes there was some breakdown though at the higher levels. There was still some pronunciation issues at times "Städte/Bevölkerung' and difficulties with plural (die Bereich) and article endings (ein Tabelle) at times (which I did not notice so much with Spanish). In real struggles, the verb would just fail to be there "dann als Abschluss...einen kleinen Blick...." - at this point the student just lowered the level to simplify their grammar and structure. From this experience, and comparing to later classes, students made strides from the first to the second presentation (as 'scaffolding' a presentation itself become more refined, both future instructors and students have shown to have made greater strides). Gaining confidence in presenting more freely (i.e. with less note cards or none at all), re-formulating and re-casting explanations, introducing, giving outlines, then developing and connecting parts (slides) in working through their presentations and 
finally concluding (not just saying "das ist alles"). There is a definite language development and refinement taking place in this process which positively overlaps into a broad array of overall language tasks and thus proficiency. Furthermore, many of the students developed a sense of their presenting style and what it is a presentation is. Here they greatly raised their consciousness of their audience and made the whole experience more fruitful for everyone involved, which is a plus for their language skills as well as over transferrable skills in presenting (in academic and professional realms).

In working with presentational language and in particular, presentations in second-year Spanish and German, it is very apparent that the book market for this topic is developed, and continues to expand in German, whereas in Spanish, there is a definite niche to be filled. Not many professional or didactic sources were referenced in Spanish (from original scaffolding in the Winter and Spring of 2012), however there were numerous sources in German. For example, for German, Shroedel's (2009) Lernplus+ Die Lernhilfe fürs Gymnasium Referate und Präsentationen has proven an interesting work and shows concern for the topic/activity of giving presentations in Germany. It works through a stepby-step process of what is a presentation, with exercises and checklists through practicing and then giving it. The focus is for academically oriented High-Schoolers (in German Gymnasium), but could serve as a guide and great reference across levels and ages. Amongst the many newer books (from 2006-now) Methoden-Magazin also includes links to audio and video examples, which is very encouraging and potentially useful. There is a plethora of more professionally, business minded books as well (i.e. for marketing, start-up proposals, job interviews, etc..) which outline theory, structure and language (to lesser extent) in presenting.

\section{DisCUSSION AND CONCLUSION}

Scaffolding for a presentation in Spanish and then German has presented encouraging and interesting results. First, native English speakers (of which my classes were overwhelmingly composed) learning Spanish obviously would be a bit further along with their second language at the beginning of the second-year than their peers learning German, but both were/are able to engage and progress using similar scaffolding/activities (to note here: not all students native English speakers, especially in German and a growing number of students are already fully bilingual (mostly English/Spanish if in German or English/Chinese in both Spanish and German classrooms) when entering into my foreign language classroom or are entering into their second foreign language). This said; there were some notable differences to be mentioned. Both were able introduce their themes, then connect to why they are interested in this and thus presenting (also hoping to connect to audiences' interest), give a short overview of their presentation, begin and present information, connecting points and then concluding. Both audiences were able to ask critical questions (German audience struggled a bit more with contextualizing their questions at times) and presenters were able to successfully field questions (I would say the German language presenters - at times - struggled a slight bit more, spontaneously responding at a higher level - although not exclusive). There seemed to be a bit more break-down at times (conjugation, word order) when some of the students reached to the higher levels in German, whose structure though (word order especially, also adjective endings) are a bit more complicated. To consider here, in connecting clauses and relative pronoun clauses, one can use 'que' (that) in Spanish quite loosely (develops with more sophistication and precision into cual, lo que, lo cual as well as with prepositions) where as in German, one needs to reference back to the definite article, knowing it's gender and then case-function in the ensuing clause (der, die, das, die, then is it nominative, accusative, dative or genitive, with prepositional use a third complication), which is a bit more complicated and hence limiting at this stage in language acquisition. However, into the second and third quarters, these structures become more frequent and more confidently used. Continuing on, at times the integration of higher vocabulary/the topic itself was not well integrated (in both languages) - i.e. going beyond just static presentation of information, but making accessible to audience and making it coherent within the ('your') presentation (i.e. connected, flow, not fragmented). However, with a greater number of cognates in Spanish, there were usually slightly fewer moments of awkwardness. Use of past tense sometimes broke down in explanations in both Spanish and German - i.e. going into present or mixing present and past, although sentence structure usually remained (in Spanish, perfect/imperfect became less clear, in German the use of 'wenn' instead of 'als' became problematic at times). The German (also Spanish at times) students struggled hypothesizing as their command of the subjunctive was notably weaker (however - this is also a superior task for students who are bobbing between IM-IH). In the second and third classes of the second year, this tends to be expressed/utilized more correctly, frequently and more confidently (however, the Spanish subjunctive use is a bit more particular and thus, beyond stock-phrases and memorized structures, remains a struggle for a bit longer than in German, based off of my experience). Finally, the use of technology was successful in providing further space of communication outside of class as well as capturing presentations (and various warm-up and follow-up tasks) and allowing students to view themselves (and others in video clips). Learning from my Spanish experience, I toned down the dominance of presentational language and presentations a slight bit in German, more stealthily integrating aspects of function into a broader variety of tasks and activities which seemed to be more successfully digested by the students and lead to a greater jump in overall language proficiency.

In conclusion, scaffolding for presentations in both beginning second-year Spanish and German has proven a successful strategy in reaching towards higher registry language acquisition and in developing overall transferrable skills. 


\section{REFERENCES}

[1] Berman, Russell. (2013). "Humanist: Heal Thyself." The Chronicle of Higher Education Blog http://chronicle.com/blogs/conversation/2013/06/10/humanist-heal-thyself/.

[2] ACTFL Guidelines. (2013). http://www.actfl.org/.

[3] Benjamin, Walter. (1928). Einbahnstraße. Rowohlt: Berlin.

[4] Gerlang Curricular Documents and Proficiency Objectives in Second-Year. (2013). https://www.stanford.edu/dept/lc/language/documents/GermanY2Curriculum.pdf.

[5] Su Excelencia. (1967). Film. Directed by Miguel Delgado, starring Cantiflas. Mexico, Colombia Pictures.

[6] Turneaure, Bridgette. (1996). Der treffende Ausdruck. New York: W.W. Norton and Co.

[7] Enzensberger, H.M. (1970). Baukasten zu einer Theorie der Medien. Kursbuch 20, S.159-186.

[8] Lernplus - Die Lernhilfe fürs Gymnasium: Referate und Präsentationen. (2009). Leipzig: Schroedel Verlag.

[9] Methoden-Magazin: Rhetorik und Präsentation in der Berufsschule: Mit Unterrichtsideen, Kopiervorlagen und Videotraining (auf DVD). (2008). Weinheim: Beltz.

[10] Spanlang Curricular Documents and Proficiency Objectives for Second-Year. https://www.stanford.edu/dept/lc/language/documents/SpanishY2Curriculum.pdf.

[11] Die Sprache der Präsentation: Die deutsche Sprache im wirtschaftlichen und geschäftlichen Alltag. (2005/2007). Powerpoint EFOS. oliver.efos.hr/nastavnici/mhocenski/Die-Sprache-der-Prasentation.ppt.

[12] Euba, Nikolaus and Prisca Augustyn. (2007). Stationen. Cengage Learning: Stamford.

[13] Tucholsky, Kurt. (1930). "Ratschläge für einen schlechten Redner. Vossische Zeitung, Nov. 16.

[14] Valdez, Juan. (2011). Tracing Dominican Identity. New York: MacMillan.

[15] Eisman, Volker. (2006). Training berufliche Kommunikation. Erfolgreich bei Präsentationen. Berlin: Cornelson.

Paul Nissler is a lecturer in Spanish and German and coordinates the German Language Program at the Language Center at Stanford University. He completed his Ph.D. at Pennsylvania State University in 2006. He has published and continues to research on a broad array of topics concerned with German and Spanish/Latin American literary space and language. 